\title{
OX40L-expressing Oncolytic Adenovirus DNX-2440
}

National Cancer Institute

\section{Source}

National Cancer Institute. OX40L-expressing Oncolytic Adenovirus DNX-2440. NCI

Thesaurus. Code C160192.

A selectively replication competent oncolytic adenovirus that is eng ineered to express OX40 lig and (OX40L) with potential oncolytic and immunostimulatory activities. Upon administration, OX40L-expressing oncolytic adenovirus DNX-2440, which contains an integrin binding RGD-4C motif, infects tumor cells in a Coxsackievirus-adenovirus receptor-independent manner and selectively replicates in tumor cells that are defective in retinoblastoma gene $(\mathrm{Rb})$ or cyclin-dependent kinase inhibitor-2A (p16). Tumor cell selectivity is achieved through a 24-base pair deletion in the E1A gene, which renders the oncolytic adenovirus unable to replicate in normal cells that maintain a functional $\mathrm{Rb}$ pathway, but fully replication competent in Rb/p16 defective tumor cells. Active replication of the OX40L-expressing oncolytic adenovirus DNX-2440 within tumor cells may induce oncolysis and release of OX40L. OX40L may then bind to and activate signaling pathways downstream of its cognate receptor, tumor necrosis factor receptor superfamily member 4 (TNFRSF4; OX40), which is expressed on activated T-cells. OX40L/OX40 binding promotes increased cytokine production, which can induce proliferation of memory and effector T-lymphocytes and promote the killing of nearby tumor cells. OX40L, a cell surface glycoprotein and member of the tumor necrosis factor (TNF) ligand family, provides a co-stimulatory signal for the proliferation and survival of activated Tcells. The Rb gene product and p16 are negative regulators of the cell cycle and are defective in certain tumor types. 